\title{
Disclosure failures in England and Wales: Causes, controversies and challenges
}

\section{Editorial}

This special issue of the International Journal of Law, Crime and Justice is dedicated to the timely topic of disclosure failures in England and Wales. Failures around pre-trial disclosure have gained much media attention in the last few years, with cases such as that of Liam Allan, whose rape trial collapsed after the late disclosure of electronic messages, attracting much attention. However, old and new controversial issues that affect post-conviction disclosure are perhaps lesser known to the wider audience. This special issue considers both pre-trial and post-conviction disclosure, and it aims to bring these issues to a larger multidisciplinary audience as these problems do affect several different criminal justice agencies. A failure to disclose relevant material may result in a wrongful conviction, and once that conviction has happened, it is almost impossible to get access to any documents and materials postconviction. Whilst the focus of this special issue is on England and Wales, disclosure failures are not unique to this jurisdiction, and therefore, the problems and potential solutions presented herein are of wider interest.

In the first article of this special issue, authors Almazrouei, Dror and Morgan present a forensic disclosure model, and ask important questions of what should be disclosed to, and by, forensic experts. According to the authors, legal disclosure issues have predominantly focused upon what evidence the prosecution provided or withheld from the defence. In the article, they expand the concept of disclosure to wider contexts in which disclosure failures may result in miscarriages of justice. The authors introduce a conceptual model of 'forensic disclosure' which addresses what information should be disclosed to forensic examiners, as well as what information should be disclosed by forensic examiners. The article presents a holistic overview of the dynamic interactions of four categories of stakeholders: forensic services, investigation, legal, and external stakeholders. The authors discuss the effective implementation of the forensic disclosure model by addressing five questions: when / what / how / who / why - should information be best given to, and by, forensic examiners in order to increase the quality of forensic decision making and to minimise bias.

The second article, written by McCartney and Shorter, move on to consider how controversial issues with post-conviction disclosure exacerbate injustices. Following years of debate, the creation of the Court of Appeal (Criminal Division) in England and Wales signified official recognition that the criminal process may sometimes result in unsafe convictions. Central to the operation of the appellate system, is the ability of individuals who claim that their conviction is in error, to revisit and re-examine evidence gathered during the investigation, as well as that relied upon at their trial. High-profile miscarriages of justice have often only been remedied when there has been defence access to materials post-conviction (which had often not been disclosed pre-trial). While there has (rightly) been critical attention paid to pre-trial non-disclosure and the risks this poses to justice, such scrutiny has been lacking postconviction. And yet, it is arguable that the rationale of preventing miscarriages of justice 
underpinning the duties of pre-conviction disclosure, subsists post-conviction. However, the UK Supreme Court judgment in R (Nunn) v Chief Constable of Suffolk Constabulary \& Anor. [2014] UKSC 37 has made it more difficult to gain disclosure post-conviction. The article details a worrying picture of inconsistency among police and prosecution authorities, with confusion over what should be retained (and how), and whether disclosure post-conviction should be permitted. It concludes that without significant intervention and reform, miscarriages of justice will continue uncorrected and the appellate system will become inconsequential.

In the third article, Greenwood and Eady consider the argument of 'better late than never' when it comes to disclosure. The authors argue that the recent instances of fundamental failings in pre-trial disclosure should also place systemic procedures for post-conviction disclosure firmly in the spotlight. Drawing on the authors' experience of working on university miscarriage of justice projects, the article argues that the UK Supreme Court decision in $\mathrm{R}$ (Nunn) v Chief Constable of Suffolk Constabulary \& Anor. [2014] UKSC 37 must be revisited to strengthen the duty of disclosure of material post-trial, and to provide sanctions for authorities that fail to comply. In the current climate of austerity, there is increasing reliance on student projects and other similar organisations to assist appellants post-conviction; it is necessary to determine what their role should be and what rights they might have to access material on behalf of defendants. The article concludes by suggesting that fairness demands for consideration to be given to proposals in the "Open Justice Charter," which is a document drafted by several academics and practitioners in the field of criminal appeals.

In the fourth and final article, Henneberg asks whether conviction integrity units (CIUs) modelled on those in the USA could be a solution to the issues associated with post-conviction disclosure in England and Wales. Conviction integrity units operate out of a small number of prosecutors' offices in the USA, and these have since 2007 contributed to several exonerations. In England and Wales, there are obstacles in place that prevent post-conviction disclosure for virtually anyone other than the Criminal Cases Review Commission (CCRC), the body that in effect screens cases for the Court of Appeal (Criminal Division). The article examines whether CIUs modelled on those in the USA could be the way forward to help those who have been wrongfully convicted. It is concluded that such units could be useful in England and Wales, and may benefit from being run by a publicly elected post similar to the Police and Crime Commissioners (PCCs) implemented in 2012, as this would ensure greater democratic governance and oversight. It is further concluded that improved third party access to postconviction disclosure is urgently needed.

Marika Henneberg (special issue editor) Institute of Criminal Justice Studies

University of Portsmouth, United Kingdom E-mail address: marika.henneberg@port.ac.uk 